\title{
GLASS MATERIALS FOR OPTICAL FIBERS
}

\author{
IVAN KASIK, VLASTIMIL MATEJEC, MILOS HAYER, MICHAL KAMRADEK, \\ ONDREJ PODRAZKY, JAN MRAZEK, PAVEL PETERKA, PAVEL HONZATKO \\ Institute of Photonics and Electronics, Czech Academy of Sciences \\ Chaberská 1014/57, 18251 Prague, Czech Republic \\ "E-mail: kasik@ufe.cz
}

Submitted August 20, 2019; accepted October 14, 2019

\begin{abstract}
Keywords: Optical fibers, Silica glass, MCVD, Fiber lasers
Optical fibers represent the key component of modern optical telecommunication networks. Such fibers are based on silica glass of high purity usually modified with several percent of glassforming oxides such as $\mathrm{GeO}_{2}$ and $\mathrm{P}_{2} \mathrm{O}_{5}$. These materials with minimum optical losses around $1.5 \mu \mathrm{m}$ are transparent up to $\sim 2 \mu \mathrm{m}$. In this paper, the attention is focused on silica glass materials doped with ions of rare-earth elemens for fiber lasers and fiber amplifiers. Since rare earths cause phase separation only in small amount incorporated into silica glass, ternary systems containing $\mathrm{P}_{2} \mathrm{O}_{5}$ or $\mathrm{Al}_{2} \mathrm{O}_{3}$ have been investigated. Latest results in $\mathrm{GeO}_{2}$-based glasses transparent in mid infrared region are also presented.
\end{abstract}

\section{THEORETICAL}

Conventional silica-based glass materials with minimum optical losses arounnd

$1.5 \mu \mathrm{m}$ for telecommunications

In 1966 Charles Kuen Kao published a paper called „Dielectric-fibre surface waveguides for optical frequencies" [1] in which he outlined fundaments of optical communications based on highly transparent silica glass optical fibers. For this groundbreaking paper and lifework in the field of optical fibers he was awarded by the Nobel Prize in 2009. Kao predicted that modern and fast optical communications can be performed only with thin silica-based fibers of ultra-high purity leading to their minimum optical losses in near infrared region around $1500 \mathrm{~nm}$. He also noticed that impurities as for example $\mathrm{Fe}^{3+}, \mathrm{Cu}^{2+}, \mathrm{Cr}^{3+}, \mathrm{OH}^{-}$etc. can be present in such silica glass maximally in ppm amount otherwise the optical losses are unacceptably increased making the fibers useless. It was a challenge for technologists since it is extremely difficult to achieve such level of purity especialy during high-temperature processes which in the case of processing of silica glass are of around $2000-2100{ }^{\circ} \mathrm{C}$. Therefore, an alternative research was guided to find a suitable multicomponent glasses or polymers of much lower processing temperature. However, two orders higher optical losses were achieved with polymer or multicomponent based fibers [2-3]. Kao's requirements finally answered in Corning and fabricated silica glass rod (so called preform) of high purity from which the first optical fiber of acceptable optical losses $<20 \mathrm{~dB} \cdot \mathrm{km}^{-1}$ was drawn [4].
The essential optical rule of higher refractive index of optical core than that of cladding was achieved in this case by coating of the silica glass core with a polymer of lower refractive index. Such generation of optical fibers drawn from single component silica rods - preforms was called Polymer-Clad-Silica (PCS) and their structure was characterized by a simple step-index profile of refractive index. Production of more complex fiber structures with glass cladding and glass core of tailored refractive-index profile required more sophisticated technology. Diffusion of multicomponent core of higher refractive index into silica cladding tube was tested [5] but without a significant impact. Next breakthrough in this field introduced elaboration of the Outside Vapor Deposition [6] and of the Modified Chemical Vapor Deposition (MCVD) methods [7]. The MCVD was presented for the first time by J.B. McChesney [8] at the $10^{\text {th }}$ International Congress on Glass in Kyoto 1974; the ICG was at that time a usual platform for presentation of achievements in this field.

The MCVD method is based on sintering of smooth silica particles onto inner wall of rotating silica substrate tube. Fine $\mathrm{SiO}_{2}$ particles (,soot") are formed by oxidation of $\mathrm{SiCl}_{4}$ vapors at temperatures around $1600-2000{ }^{\circ} \mathrm{C}$. Since $\mathrm{SiCl}_{4}$ is a volatile liquid of boiling point of around $60{ }^{\circ} \mathrm{C}$, by its distillation it is possible to achieve high level of purity and to produce a silica glass of ultra-high purity. The glass is deposited gradually into substrate tube in form of layers of thickness of 1 - $20 \mu \mathrm{m}$; finally the tube with layers is collapsed into a preform. High quenching rate $\left(\sim 10^{2}{ }^{\circ} \mathrm{C} \cdot \mathrm{s}^{-1}\right)$ accompanies the deposition because of small dimensions of the layers. 
A difference of refractive index of silica fabricated by melting (Heraeus F300) and silica deposited by the MCVD can be seen in Figure 1.

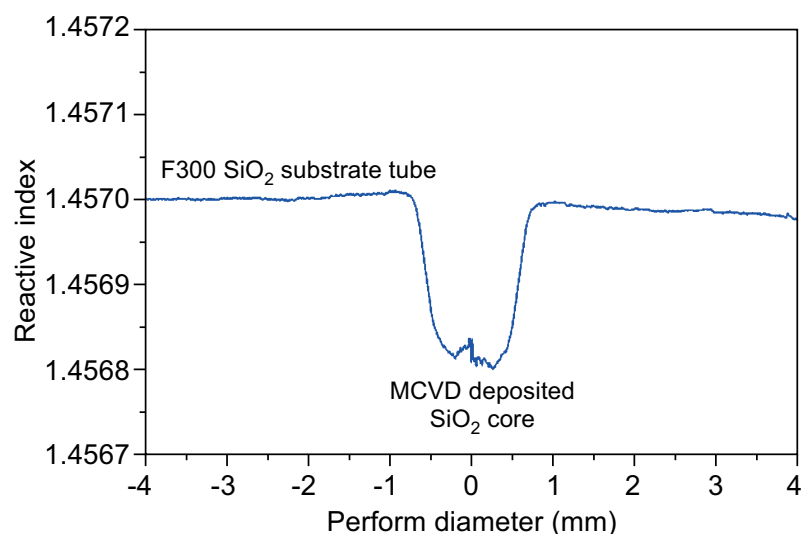

Figure 1. Refractive index of preform composed from silica glass F300 fabricated by melting (the outer part corresponding to substrate tube) and silica glass deposited by the MCVD around axis (measured at wavelength $633 \mathrm{~nm}$, temperature $21^{\circ} \mathrm{C}$, pressure $101 \mathrm{kPa}$ ).

When the layers are doped with compounds modificating refractive index, preforms of complex refrac-tiveindex profile can be produced. Number of glass compositions was investigated for this purpose. Conditions such as good miscibility with silica glass, glassforming, close expansion coefficient, low optical losses, availability of starting materials and reasonable dependence of refractive index on glass composition belong to basic criteria for choice of glass composition of the layers [9]. Silica doped with $\mathrm{B}_{2} \mathrm{O}_{3}$ or fluorine exhibit lower refractive index than pure silica [10-11]. Binary or ternary systems, E.g. $\mathrm{GeO}_{2}-\mathrm{SiO}_{2}, \mathrm{P}_{2} \mathrm{O}_{5}-\mathrm{SiO}_{2}, \mathrm{TiO}_{2}-\mathrm{SiO}_{2}, \mathrm{Sb}_{2} \mathrm{O}_{3}-$ $-\mathrm{SiO}_{2}, \mathrm{Al}_{2} \mathrm{O}_{3}-\mathrm{SiO}_{2}, \mathrm{GeO}_{2}-\mathrm{P}_{2} \mathrm{O}_{5}-\mathrm{SiO}_{2}$ exhibit higher refractive index [12-17]. Finally, $\mathrm{GeO}_{2}$-doped silica cores and $\mathrm{P}_{2} \mathrm{O}_{5}$-doped silica claddings were globally established as materials transparent in visible and near infrared spectral region of minimum optical losses suitable for telecommunications.

The Czechoslovak and Czech footprint in this field followed the global leaders with a little delay. Multicomponent soft-glass-based fibers of typical composition $\mathrm{K}_{2} \mathrm{O}-\mathrm{As}_{2} \mathrm{O}_{3}-\mathrm{PbO}-\mathrm{SiO}_{2}$ were investigated in Glass Research Institute, Hradec Kralove [18]. Another team for investigation of silica optical fibers was established within Joint Laboratory Silicates of the Czechoslovak Academy of Sciences and the Institute of Chemical Technology in 1979. The first technology of PCS optical fibers was completed in 1982 employing the US Centorr graphite resistive furnace for $2100{ }^{\circ} \mathrm{C}$ [19]. Technology of graded-index (GI) and single-mode (SM) telecom fibers based on ternary $\mathrm{GeO}_{2}-\mathrm{P}_{2} \mathrm{O}_{5}-\mathrm{SiO}_{2}$ materials [20] was developed nearly at the same time. Spectral attenuations of discussed materials can be found in Figure 2.
Attenuation of $20 \mathrm{~dB} \cdot \mathrm{km}^{-1}$ represents a limit for practical use of the optical fibers in telecommunications allowing transmission of $1 \%$ of input light through a distance of $1 \mathrm{~km}$. All these technologies were transfered to pre-industrial production in VUSU Teplice.

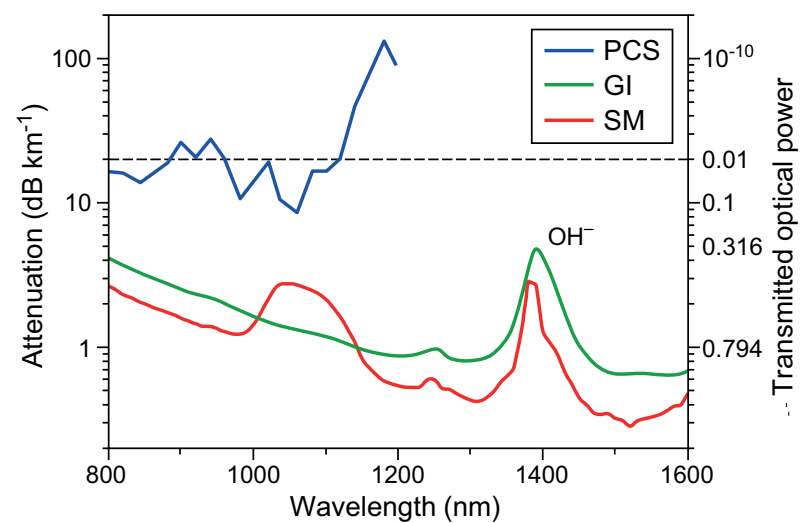

Figure 2. Spectral attenuation of several generations of silicabased optical fibers for telecommunications.

Independently, intensive research of chalcogenide glasses of $\mathrm{Ge}-\mathrm{Se}-\mathrm{Te}$, Ge-As-Se-Te composition for optical fibers transparent in infrared spectral region up to $10 \mu \mathrm{m}$ was performed [21]. Optical losses of these materials prepared by conventional melting were not suitable for long-haul optical communications but sufficient for many other applications such as spectroscopy, optoelectronics etc.

New materials for fiber sensors, fiber lasers and amplifiers operating up to $2 \mu \mathrm{m}$

Later on, after telecommunication crisis at the beginning of new millennium, optical fibers penetrated to the field of optical fiber sensors, fiber lasers and amplifiers. Low optical losses are not so important in these applications since only short lenghts of fibers are used. But specific properties like tailored refractive index or fluorescence are appreciated. Among others, specialty fibers drawn from $\mathrm{GeO}_{2}$-highly-doped silica preforms with inverted refractive index were developed for evanescent-wave sensors. Cores of such fibers contained 50 mol. \% $\mathrm{GeO}_{2}$ [22] or even 97 mol. \% $\mathrm{GeO}_{2}$ [23]. Such binary glass cores were surrounded by silica substrate tube F300 of more than one order lower expansion coefficient and preforms of centimeters dimensions had to be carefully annealed to prevent crashing (Figure 3). Transparency of such highly-doped fibers stayed limited to cca $2 \mu \mathrm{m}$.

High content of $\mathrm{GeO}_{2}$ in silica glass enhances photorefractive properties of the fiber cores and so supports inscription of Fiber Bragg Gratings (FBG) into these fibers. This effect is widely used in FBG sensors and for formation of laser cavity of fiber lasers. 
Optical fibers drawn from F2 Schott glass preforms (of refractive index 1.62 and of $\mathrm{Na}_{2} \mathrm{O}-\mathrm{K}_{2} \mathrm{O}-\mathrm{As}_{2} \mathrm{O}_{3}-\mathrm{PbO}-$ $-\mathrm{SiO}_{2}$ composition) were succesfully prepared and used for monitoring of polymer composites [24]. An increase of several ordes of attenuation of such F2 fiber in comparison to silica glass fibers can be seen from Figure 4 and Figure 2.

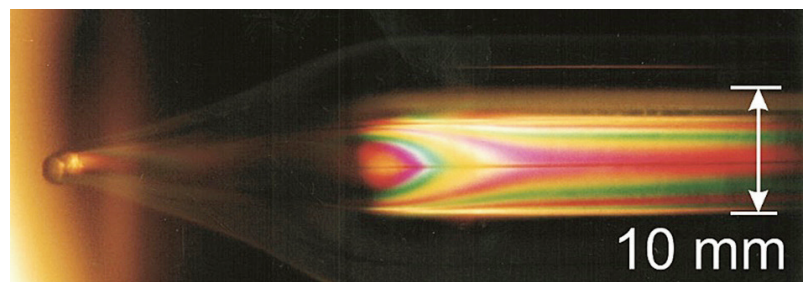

Figure 3. Stress in highly $\mathrm{GeO}_{2}$-doped preform observed in polarized light.

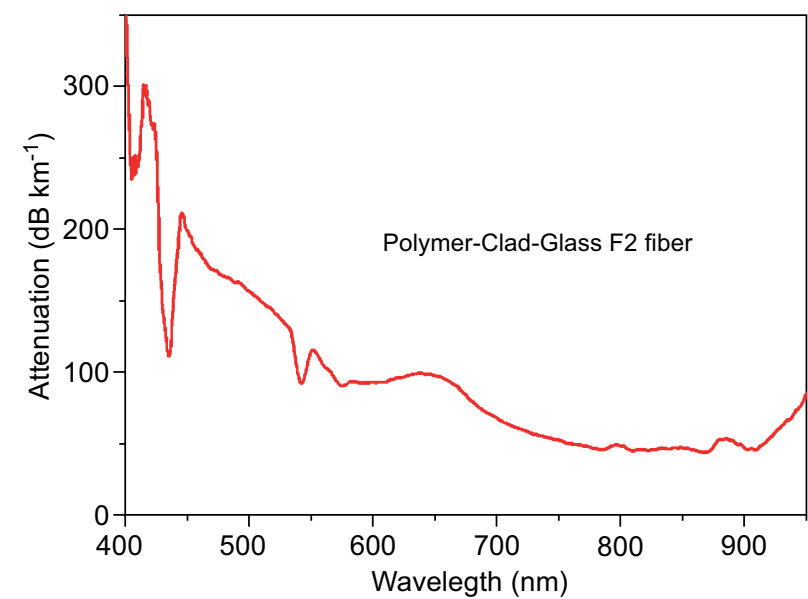

Figure 4. Spectral attenuation of Polymer-Clad-Glass optical fiber drawn from F2 glass preform.
Boom in fiber lasers and amplifiers started at Optoelectronics Research Center University of Southampton [25] a long time after publication of the pioneering work of E. Snitzer [26]. Significant part of these devices is based on materials doped with ions of rare-earths elements (RE). These fluorescent agents are capable to withstand high processing temperatures of silica glass. Materials doped with erbium were investigated at fist because of their fluorescence around $1550 \mathrm{~nm}$ which is the conventional wavelenghts used in telecommunications. However, only small amount of around hundreds of ppm of RE in silica glass leads to phase separation [27] and to devastation of optical properties of the material. So, in order to achieve higher RE content in glass the matrix had to be modified with modifiers supporting dissolution of RE and compensating their charge. Modification of the silica matrix with $\mathrm{GeO}_{2}$ did not lead to fundamental progress [28]. But introducing of $\mathrm{Al}_{2} \mathrm{O}_{3}$ was highly effective and made doping of fibers with higher content of RE possible. Aluminum oxide is able to exist in modifications of $\mathrm{Al}_{2} \mathrm{O}_{3}$ as well as of $\left[\mathrm{Al}_{2} \mathrm{O}_{4}\right]^{2-}$ depending on its vicinity and in this way it can compensate the $\mathrm{RE}$ ions. Glassforming properties of ternary $\mathrm{RE}-\mathrm{Al}_{2} \mathrm{O}_{3}-$ $-\mathrm{SiO}_{2}$ systems of bulk samples were investigated by Shelby [29]. $\mathrm{Al}_{2} \mathrm{O}_{3}$ also positively increases refractive index of glass and so it is widely used for modification of core of optical fibers up to 10 - $12 \mathrm{~mol}$. \% typically [17], [30]. $\mathrm{Al}_{2} \mathrm{O}_{3}$ is also used for modification of silica glass matrix doped with thulium or holmium ions because of its positive influence on fluorescence lifetime of the materials [31]. Since starting materials for $\mathrm{Al}_{2} \mathrm{O}_{3}$ and $\mathrm{RE}$ doping are available only in solid state, number of modifications of the MCVD technology were developed [32-34]. Glass matrices of fibers for ytterbium fiber lasers are usually co-doped with several molar percent of $\mathrm{P}_{2} \mathrm{O}_{5}$ [35]. In vicinity of $\mathrm{Yb}^{3+}$ the double bond $\mathrm{P}=\mathrm{O}$ is

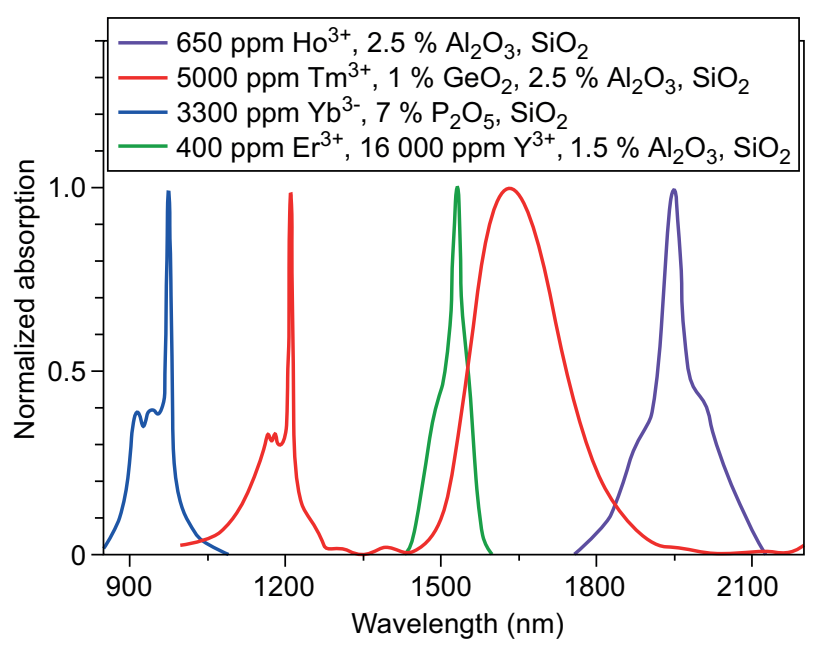

a)

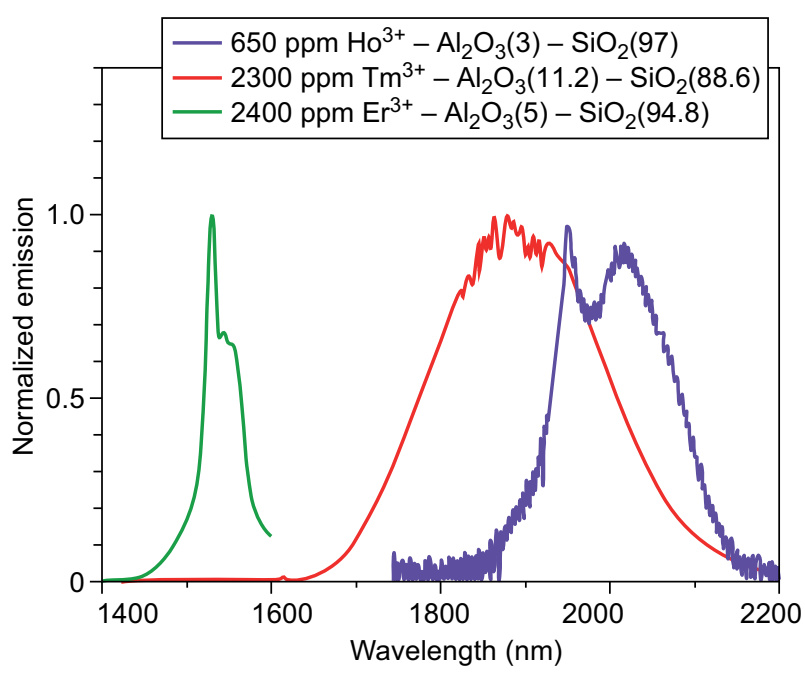

b)

Figure 5. Example of spectra of specialty optical fibers doped with $\mathrm{Er}^{3+}, \mathrm{Yb}^{3+}, \mathrm{Tm}^{3+}$ and $\mathrm{Ho}^{3+}$ in silica based glass matrix modified with $\mathrm{Al}_{2} \mathrm{O}_{3}$ or with $\mathrm{P}_{2} \mathrm{O}_{5}$ : a) absorption spectra, b) emission spectra. 
split and compensates the ions in glass structure. Fibers of composition $\mathrm{Yb}^{3+}-\mathrm{P}_{2} \mathrm{O}_{5}-\mathrm{SiO}_{2}$ are frequently used for $\mathrm{kW}$-class fiber lasers operating at around $1060 \mathrm{~nm}$. Excitation and fluorescence spectra of $\mathrm{Er}^{3+}, \mathrm{Yb}^{3+}, \mathrm{Tm}^{3+}$ and $\mathrm{Ho}^{3+}$-doped silica optical fibers can be seen at Figure 5.

An idea of enhancement of fluorescence of RE by means of nanoparticle technology was brought up a decade ago. Metallic nanoparticles were implemented at first, later fluorides, ceramics and finally a nano-phase separation processes were developed [36]. This issue is still widely investigated [37-39] with ambiguous conclusions. According to [40] when alumina nanoparticles are incorporated into silica matrix, mullite phase is formed after high temperature processing (preform collapsing and fiber drawing) in agreement with $\mathrm{Al}_{2} \mathrm{O}_{3}-$ $-\mathrm{SiO}_{2}$ phase diagram [41] and no significant improvement of lasing properties was observed. This conclusion can be indirecly supported by the results observed with sapphire-core fiber drawing [42].

\section{Latest trends}

Silica-based optical glasses have been employed for decades as fundament for optical applications in spectral region up to $\sim 2100 \mathrm{~nm}$. Requirements for materials transparent at longer wavelenghts has appeared namely in relation to the latest advance in infrared lasers. Optical fibers from such materials should be capable to transmit infrared radiation or to produce stimulated infrared fluorescence as fiber lasers. Extensive research has been executed in fluoride, chalcogenide, telluride and other non-oxide glasses transparent in infrared region and suitable for fiber drawing, including domestic research of $\mathrm{As}_{2} \mathrm{~S}_{3}$ passive optical fibers [43].

$\mathrm{GeO}_{2}$-based glasses were investigated from the group of oxidic glasses potentially transparent in mid infrared region. Such glass matrix could be suitable for embedding of RE and could be a suitable medium for transmission of their fluorescence up to $4-5 \mu \mathrm{m}$. However, it is not easy to fabricate such glass because of its relatively high processing temperature around $1500{ }^{\circ} \mathrm{C}$. Therefore, $\mathrm{GeO}_{2}$ glass matrix was modified with $\mathrm{PbO}$ up to $32 \mathrm{~mol} . \%$ at the begining. Transparent samples of good optical quality and preform shape were produced (Figure 6a) but lead oxide cannot be considered a perspective material because of its toxicity. Pure $\mathrm{GeO}_{2}$ glass samples were melted in extra dry atmosphere and results were presented again at ICG [44]. Homogeneous transparent samples were obtained as expected but intensive hygroscopicity was observed later (Figure 6b).

Fluorescence spectrum of $\mathrm{Er}^{3+}-\mathrm{PbO}(32)-\mathrm{GeO}_{2}(68)$ glass sample containing $400 \mathrm{ppm}^{3+}$ can be seen in Figure 7. Despite a good homogeneity and transparency of $\mathrm{GeO}_{2}$ glass samples already prepared, a search for suitable modifier decreasing the processing temperatures and keeping transparency in mid infrared region is a challenge for future research.

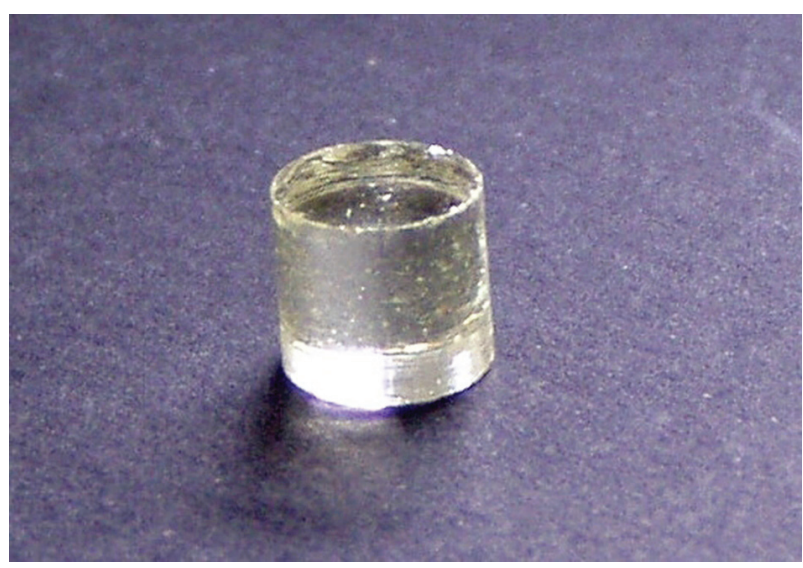

a)

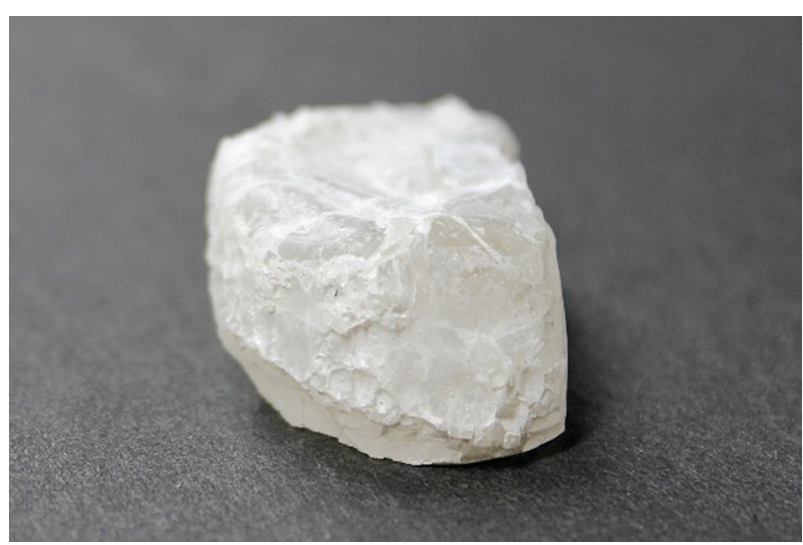

b)

Figure 6. Samples of preforms of: a) $\mathrm{PbO}-\mathrm{GeO}_{2}$ glass, b) $\mathrm{GeO}_{2}$ glass exposed to free apmosphere.

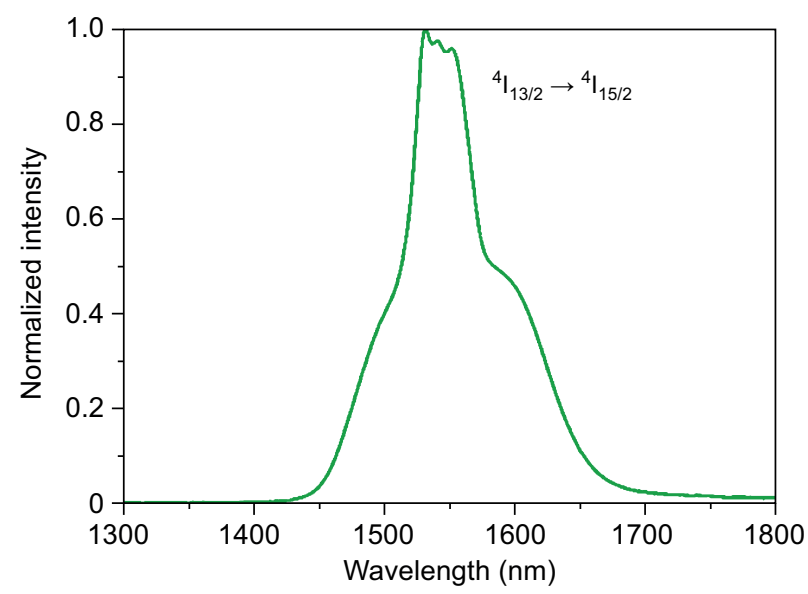

Figure 7. Fluorescence spectra of $\mathrm{Er}^{3+}-\mathrm{PbO}-\mathrm{GeO}_{2}$ glass excited at $525 \mathrm{~nm}$.

Small dimensions of optical fibers and their flexibility make them perfectly suitable for use in medicine. Number of diagnostic or terapeutic tools based on optical soft glass fibers or silica fibers have been widely produced. Recently, requirements for biodegradable optical fibers has appered. Using of biodegradable fibers for in-vivo applications would significantly decrease the 
risk of consequences of potential breaking of fiberoptic tools. Phosphate-based optical fibers could be an answer to this call [45] as an alternative to fibers from biodegradable polymers [46].

\section{CONCLUSIONS}

A survey on glass materials used for optical fibers was given with accent on results achived within 40 years of fiber-optics research in Joint Laboratory of Silicates, later Institute of Chemistry of Glass and Ceramics Materials ASCR, later Institute of Radioengineering and Electronics CAS, later Institute of Photonics and Electronics CAS and Laboratory of inorganic materials of the Institute of Rock Structure and Mechanics CAS. From this survey, it can be concluded that the pioneering vision of Charles K. Kao was extraordinarily viable and predicted trends in optical communications for decades. Silica-based optical fibers are nowadyas object of mass production as well as of intensive research and related technologies, thus representing symbols of matured economies.

\section{Acknowledgement}

This research has been supported by the Czech Science Foundation, project. No 17-20049. Authors would like to ask for understanding of high portion of self-citations related to commemoration of 40 years anniversary of the research of technology of optical fibers conducted in the Czech Republic.

\section{REFERENCES}

1. Kao K.C., Hockham G.A. (1966): Dielectric-fibre surface waveguides for optical frequencies. Proceedings of the Institution of Electrical Engineers, Part J, Optoelectronics, 113, 1151-1158.doi: 10.1049/piee.1966.0189

2. Brussaard G., Watson P.A. (1978): Low loss and low $\mathrm{OH}$ content soda-lime silica glass fiber. Electronics Letters, 14 (5), 150-151. doi: 10.1049/el:19780101

3. Beales K.J., Duncan W.J., Newns G.R. (1975). Sodium borosilicate glass for optical fibers. In: Proc. $1^{\text {st }}$ ECOC. London, pp. 27-29.

4. Maurer R.D. (1973): Glass fibers for optical communications. Proceedings of the IEEE, 61, 452-462. doi: 10.1109/ PROC.1973.9059

5. Newns G.R. (1976). Composed glasses for optical fibers. In: Proc. $2^{\text {nd }}$ ECOC, Paris, pp. 21-26.

6. Pinnow D.A., Dabby F.W., Camlibel I., Warner A.W., Van Uitert L.G. (1975): Preparation of high purity silica. Material Research Bulletin, 10, 1263-1266. doi: 10.1016/ 0025-5408(75)90084-7

7. Nagel S.R., McChesney J.B., Walker K.L. (1982): An overview on the Modified Chemical Vapor Deposition (MCVD) process and performance. IEEE Journal of Quantum Electronics, QE-18, 459-476.
8. MChesney J.B., O'Connor P.B., Presby H.M. (1974): A new technique for preparation of low-loss and graded index optical fibers. Proceedings of the IEEE, 62, 1278-1279. doi: 10.1109/PROC.1974.9608

9. Miller S.E., Chynoweth A.G. (1979). Optical telecommunications. Academic Press.

10. Camlibel I., Pinnow D.A., Dabby F.W. (1975): Optical aging characteristics of borosilicate clad fused silica core fiber optical waveguides. Applied Physics Letters, 26, 185-187. doi: 10.1063/1.88109

11. Kirchhof J., Unger S., Knappe B. (2008): Fluorine containing high-silica glasses for speciality optical fibers. Advanced Materials Research, 39-40, 265-268. doi: 10.4028/ www.scientific.net/AMR.39-40.265

12. Ghigo G., Modone E., Parisi G., Roba G. (1985), $\mathrm{GeO}_{2}$ doped high NA multimode fiber made by pressurized MCVD. In: Proc. SPIE 584 - Optical fiber characteristics and standards, pp. 26-32. doi: 10.1117/12.950953

13. McAfee K.B., Gay D.M., Walker K.L., Hozack R. (1985): Thermodynamic stability and incorporation of phosphorus into germanium-doped silica glass. Journal of the American Ceramics Society, 68(6), 359-362. doi: 10.1111/j. 1151-2916.1985.tb15240.x

14. Carson S.D., Maurer R.D. (1973): Optical attenuation in Ti-silica glasses. Journal of Non-Crystalline Solids, 11, 368-380. doi: 10.1016/0022-3093(73)90025-2

15. Shimizu M., Ohmori Y., Nakahara M. (1985): Fabrication of antimony oxide -doped silica fibers by the VAD process. Electronics Letters, 21(19), 872-873. doi: 10.1049/el: 19850615

16. Ohmori Y., Hanawa F., Nakahara M. (1982): Fabrication of low-loss $\mathrm{Al}_{2} \mathrm{O}_{3}$-doped silica fibers. Electronics Letters, 18(18), 761-763. doi: 10.1049/el:19820515

17. Ohmori Y., Miya T., Horiguchi M. (1983): Transmissionloss characteristics of $\mathrm{Al}_{2} \mathrm{O}_{3}$-doped silica fibers. Journal of Lightwave Technology, LT-1(1), 50-56. doi: 10.1109/JLT. 1983.1072067

18. Haladej L. (1990). Multicomponent glasses for waveguides of high numerical aperture. Project report SVUS.

19. Schatz S., Hayer M., Kuncova G., Matejec V., Hrabalova M. (1982). Influence of drawing process on tensile strenght of PCS optical fibers. In: Proc. $4^{\text {th }}$ Optical communications. Prague, pp. 33-35.

20. Havranek V., Choc Z., Gotz J., Hulinsky V. (1982). Preparation of preforms for all-glass optical fibers. In: Proc. $4^{\text {th }}$ Optical communications, Prague, 30-32. doi:

21. Lezal D., Kasik I., Gotz J. (1987): $\mathrm{Ge}_{x}\left(\mathrm{Se}_{1-\gamma} \mathrm{Te}_{\mathrm{y}}\right)_{1-x}$ glasses for optical application. Journal of Non-Crystalline Solids, 90, 557-560. doi: 10.1016/S0022-3093(87)80484-2

22. Kasik I., Matejec V., Chomat M., Hayer M., Mrazek J., Skokankova J. (2005): Silica-based optical fibres with refractive index profiles tailored in a region of 1.46-1.62 for fibre-optic chemical detection. Sensors and Actuators B-chemical, 107, 93-97. doi: 10.1016/j.snb.2004.12.114

23. Dianov E.M., Mashinsky V.M. (2005): Germania-based core optical fibers. Journal of Lightwave Technology, 23 (11), 3500-3508. doi: 10.1109/JLT.2005.855867

24. Chailleux E., Salvia M., Jaffrezic-Renault N., Matejec V., Kasik I., (2001) In situ study of the epoxy cure process using a fibre-optic sensor. Smart Materials \& Structures, 10, 194-202. doi: 10.1088/0964-1726/10/2/304

25. Mears R.J., Reekie L., Poole S.B., Payne D.N. (1985): Neodymium-doped silica single-mode fiber lasers. Electronics Letters, 21(17), 738-740. doi: 10.1049/el:19850521 
26. Koester C.J., Snitzer E. (1964): Amplification in a fiber laser. Applied Optics, 3, 1182-1186. doi: 10.1364/AO.3. 001182

27. Mazurin O.V., Strelcina M. V., Schvaiko-Schvaikovskaia T.P. (1980). Properties of glasses. Nauka.

28. Ainslie B.J., Craig S.P., Davey S.T., Barber D.J., Taylor J.R., Gomes L. (1987): Optical and structural investigation of $\mathrm{Nd}^{3+}$ in silica-based fibres. Journal of Material Science Letters, 6,1361-136. doi: 10.1007/BF01794620

29. Shelby J.E., Kohli J.T. (1990): Rare-Earth Aluminosilicate glasses. Journal of the American Ceramics Society, 73, 39-42. doi: 10.1111/j.1151-2916.1990.tb05087.x

30. Kasik I., Sysala O., Gotz J. (1992): Dopování křemenných vláken netradičními dopanty. Ceramics-Silikáty, 36, 169-179.

31. Cajzl J., Peterka P., Kowalczyk M., Tarka J., Sobon G., Sotor J., Aubrecht J., Honzatko P., Kasik I. (2018): Thulium-doped silica fibers with enhanced fluorescence lifetime and their application in ultrafast fiber lasers. Fibers, 6(3), 66, doi:10.3390/fib6030066.

32. Townsend J. E., Poole S. B., Payne D. N. (1987): Solutiondoping technique for fabrication of rare-earth-doped optical fibres. Electronics Letters, 23(7), 329-331. doi: 10.1049/ el: 19870244

33. Poole S.B., Payne D.N., Mears R.J., Fermann M.E., Laming R.I. (1986): Fabrication and characterization of low-loss optical fibers containing rare-earth ions. Journal of Lightwave Technology, 4 (7), 870-876. doi: 10.1109/ JLT.1986.1074811

34. Sysala O., Kasik I., Spejtkova I. (1991): Preparation of preforms and optical fibres containing aluminum by the solution-doping method. Ceramics-Silikaty, 35(4), 363-367.

35. Vienne G.G., Caplen J.E., Dong L., Minelly J.D., Nilsson J., Payne D.N. (1998): Fabrication and characterization of $\mathrm{Yb}^{3+}: \mathrm{Er}^{3+}$ phosphosilicate fibers for lasers Journal of Lightwave Technology, 16(11), 1990-2001. doi: 10.1109/50. 730360

36. Kasik I., Peterka P., Mrazek J., Honzatko P. (2016): Silica optical fibers doped with nanoparticles for fiber lasers and broadband sources Current Nanoscience, 12, 277-290.

37. Baker C.C., Friebele E.J., Askins Ch.G., Marcheschi B.A., Peele J.R., Kim W., Sanghera J., Zhang J., Dubinskii M., Chen Y. (2016): Nanoparticle doping for high power lasers at eye safer wavelengths. In: Proc. Laser congress 2016 (ASSL, LSC, LAC), AM3A.1.
38. Baker C.C., Friebele E.J., Burdett A.A., Rhonehouse D.L., Fontana J., Kim W., Bowman S.R., Shaw L.B., Sanghera J., Zhang J., Patnnaik R., Dubinski M., Ballato J., Kucera C., Vargas A., Hemming A., Simakov N., Haub J. (2017): Nanoparticle doping for high power fiber lasers at eyesafer wavelengths, Optics Express, 25(12), 13903-13915.

39. Kasik I., Podrazky O., Mrazek J., Cajzl J., Aubrecht J., Probostova J., Peterka P., Honzatko P, Dhar A. (2014): Erbium and $\mathrm{Al}_{2} \mathrm{O}_{3}$ nanocrystals -doped silica optical fibers. Bulletin of the Polish Academy of Sciences - Technical Sciences, 62, 641-646. doi: 10.2478/bpasts-2014-0070

40. Kamradek M., Kasik I., Aubrecht J., Mrazek J., Podrazky O., Cajzl J., Varak P., Kubecek V. (2019): Ceramic nanoparticle-doping implementation into MCVD method for fabrication of holmium- doped fibers for fiber lasers, submitted to IEEE Photonics Journal - Special Issue "Specialty Optical Fibers: Materials, Fabrication, Devices and Applications".

41. Hlavac J. (1981). Technology of silicates. SNTL.

42. Dragic P., Hawkins T., Foy P., Ballato J. (2012): Sapphirederived all-glass optical fibres. Nature Photonics, 6(9), 627-633. doi: 10.1038/nphoton.2012.182

43. Podrazky O., Matejec V., Kostka P., Pedlikova J., Basinova N., Zavadil J. (2015): Optical fibers of $\mathrm{As}_{2} \mathrm{~S}_{3}$ glasses: preparation and characterization. In: Proc. of SPIE. Vol. 9450 94501B-1. doi: 10.1117/12.2070404

44. Kamradek M., Kasik I., Peterka P., Aubrecht J., Honzatko P., Podrazky O., Mrazek J., Kubecek V. (2019). Silica- and germanate- based glasses doped with rare-earth elements for photonics devices. In: Proc. $25^{\text {th }}$ International Congress on Glass. Boston, p.16.

45. Podrazky O., Peterka P., Kasik I., Vytykacova S., Probostova J., Mrazek J., Kunes M., Zavalova V., Radochova V., Lyutakov O., Ceci-Ginistrelli E., Pugliese D., Boetti N.G., Janner D., Milanese D. (2019): In-vivo testing of a bioresorbable phosphate-based optical fiber. Journal of Biophotonics, 12(7), UNSP e201800397 doi: 10.1002/jbio. 201800397

46. Gierej A., Vagenende M., Filipkowski A., Siwicki B., Buczynski, Thienpont H., Van Vlierberghe S., Geernaert T., Dubruel P., Berghmans F. (2019): Poly(D, L-Lactic Acid) (PDLLA) Biodegradable and Biocompatible Polymer Optical Fiber. Journal of Lightwave Technology, 37(9), 1916-1923. doi: 10.1109/JLT.2019.2895220 